\title{
Erratum to: Evidence for decreased expression of APPL1 associated with reduced insulin and adiponectin receptors expression in PCOS patients
}

\author{
R. Dehghan ${ }^{1} \cdot$ M. Saidijam ${ }^{1} \cdot$ M. Mehdizadeh ${ }^{2} \cdot$ N. Shabab ${ }^{1} \cdot$ M. Yavangi ${ }^{3}$. \\ T. Artimani ${ }^{3}$
}

Published online: 24 June 2016

(C) Italian Society of Endocrinology (SIE) 2016

\section{Erratum to: J Endocrinol Invest \\ DOI 10.1007/s40618-016-0468-y}

Unfortunately, Prof. Mehdizadeh name was wrongly published in the original article. The complete correct name is Prof. M. Mehdizadeh.

The online version of the original article can be found under doi:10.1007/s40618-016-0468-y.

\section{T. Artimani}

artimani@umsha.ac.ir

1 Research Center for Molecular Medicine, Hamadan University of Medical Sciences, Hamadan, Iran

2 Cellular and Molecular Research Center, Faculty of Advanced Technology in Medicine, Anatomy Department, School of Medicine, Iran University of Medical Sciences, Tehran, Iran

3 Endometrium and Endometriosis Research Center, Hamadan University of Medical Sciences, Hamadan, Iran 